\title{
Salmonella virulence factor SpiC is involved in expression of flagellin protein and mediates activation of the signal transduction pathways in macrophages
}

\author{
Kei-ichi Uchiya and Toshiaki Nikai
}

Correspondence

Kei-ichi Uchiya

kuchiya@ccmfs.meijo-u.ac.jp

Received 24 June 2008

Revised 6 August 2008

Accepted 7 August 2008

\author{
Department of Microbiology, Faculty of Pharmacy, Meijo University, 150 Yagotoyama, Tempaku-ku, \\ Nagoya 468-8503, Japan
}

\begin{abstract}
SpiC is a virulence factor encoded within Salmonella pathogenicity island 2 (SPI-2). We have previously reported that infection of macrophages with Salmonella enterica serovar Typhimurium results in the SPI-2-dependent activation of the mitogen-activated protein kinase (MAPK) signalling pathways, leading to the expression of suppressor of cytokine signalling (SOCS)-3, which is involved in the inhibition of cytokine signalling. Here, we investigated the mechanism by which SpiC mediates the activation of signal transduction pathways in macrophages. Proteomic analysis showed that the level of FliC protein, a component of the flagellar filaments, was lower in the culture supernatant of a spiC mutant than in the supernatant from wild-type Salmonella. Furthermore, quantitative real-time RT-PCR showed that this mutant had a much lower level of fliC mRNA, indicating that SpiC regulates the transcription of FliC. We also found that the level of SOCS-3 in J774 macrophages was lower when they were infected with the fliC mutant than with wild-type Salmonella. FliC participated in the activation of MAPK pathways in Salmonella-infected macrophages, leading to the upregulation of SOCS-3 expression. Collectively, these results indicate that SpiC is involved in the expression of FliC, which plays a significant role in the SPI-2dependent activation of MAPK pathways in Salmonella-infected macrophages.
\end{abstract}

\section{INTRODUCTION}

Macrophages play a central role in host defence against many types of infection, and their function is affected by various mediators, including cytokines and eicosanoids. Gamma interferon (IFN- $\gamma$ ) is an essential contributor to macrophage activation and promotes the effective killing of pathogens that can survive within macrophages (Bhardwaj et al., 1986; Green et al., 1990; Suzuki et al., 1988; van Dissel et al., 1987). On the other hand, macrophage functions can be blocked by interleukin-4 (IL-4), IL-10 and transforming growth factor- $\beta$, as well as by prostaglandin $\mathrm{E}_{2}$ (Bogdan \& Nathan, 1993; Kunkel et al., 1988; O'Farrell et al., 1998; Strassmann et al., 1994). Pathogen-associated molecular patterns (PAMPs), which are components of bacteria and viruses, are able to induce the expression of mediators by several types of cells, including macrophages, and influence the host immune system (Janeway \& Medzhitov, 2002). PAMPs include cell wall components

Abbreviations: ERK, extracellular signal-regulated kinase; IFN, interferon; IL, interleukin; JNK, c-Jun amino-terminal kinase; MAPK, mitogenactivated protein kinase; NF- $\kappa \mathrm{B}$, nuclear factor $\kappa \mathrm{B}$; PAMP, pathogenassociated molecular pattern; SOCS, suppressor of cytokine signalling; SPI-2, Salmonella pathogenicity island 2; TLR, Toll-like receptor; TTSS, type III secretion system. derived from Gram-positive bacteria, LPS from Gramnegative bacteria, lipoteichoic acid, and flagellum, all of which are recognized by Toll-like receptors (TLRs). Specifically, bacterial cell wall components and lipoteichoic acid are recognized by TLR2 (Schwandner et al., 1999), and LPS and flagellin bind TLR4 and TLR5, respectively (Hayashi et al., 2001; Poltorak et al., 1998). Ligand binding by TLRs leads to the induction of immune and inflammatory genes (Akira \& Takeda, 2004).

Salmonellae are Gram-negative bacteria that cause a variety of disease syndromes in humans and animals. Salmonellae invade and destroy specialized epithelial cells in the host intestine, and migrate to the mesenteric lymph nodes, where they encounter, and subsequently survive and replicate within macrophages. Specific virulence factors encoded within the Salmonella pathogenicity island (SPI) are required at various stages of Salmonella infection (Groisman et al., 1999). Salmonella enterica serovar Typhimurium, which causes gastroenteritis in humans and a systemic disease in mice similar to human typhoid fever, harbours two kinds of type III protein export systems: one for flagellar proteins as described above, and one for virulence factors. Several genes from the two systems share sequences in common (Aizawa, 2001; 
Macnab, 2004). Some important virulence factors are directly delivered into the host environment by two different type III secretion systems (TTSSs) encoded on SPI-1 and SPI-2. The SPI-1 TTSS mediates bacterial entry into nonphagocytic cells (Galan, 2001), and the SPI-2 TTSS is required for survival and replication in the intracellular environment of host cells and for systemic infection in mice (Hensel et al., 1998; Ochman et al., 1996; Shea et al., 1996).

SpiC is a virulence factor encoded within SPI-2. Previous studies have shown that a strain carrying a mutation in the spiC gene is unable to survive within macrophages and has greatly reduced virulence in mice. The SpiC protein is necessary for inhibiting the fusion of Salmonella-containing phagosomes with endosomal and lysosomal compartments (Uchiya et al., 1999). Moreover, this protein is translocated by the SPI-2 TTSS to the cytosol of macrophages, where it interacts with host proteins such as TassC (Lee et al., 2002) and Hook3 (Shotland et al., 2003) to alter intracellular trafficking. On the other hand, several investigators have reported that $\mathrm{SpiC}$ is required for the translocation of SPI-2 effector proteins into target cells by interacting with SsaM, a SPI-2-encoded protein (Freeman et al., 2002; Yu et al., 2002, 2004). In addition, our recent studies have shown that SpiC is involved in Salmonella-induced activation of the signal transduction pathways in macrophages, leading to not only the production of IL-10 and prostaglandin $\mathrm{E}_{2}$ but also the expression of suppressor of cytokine signalling (SOCS)-3, which is involved in the inhibition of IL-6 and IFN- $\gamma$ signalling (Uchiya et al., 2004; Uchiya \& Nikai, 2004, 2005). As described above, the production of these mediators is thought to have an important role in the intracellular survival of Salmonella and its escape from the host defence system via modification of macrophage function.

In the present study, we investigated the mechanism by which SpiC mediates the activation of signal transduction pathways in macrophages following Salmonella infection. We found that SpiC promotes the expression of FliC at the transcriptional level. This expression of FliC activates mitogen-activated protein kinase (MAPK) signalling pathways, which play a significant role in the SPI-2-dependent induction of SOCS-3 expression by Salmonella infection.

\section{METHODS}

Bacterial strains, plasmids and growth conditions. The bacterial strains used in this study were derived from the wild-type $S$. enterica serovar Typhimurium strain 14028s. The spiR::kan derivative EG5799 and the spiC:: kan derivative EG10128 have been described by Ochman et al. (1996) and Uchiya et al. (1999), respectively. The deletion mutants of $f l i C$ and $f l j B$ gene were constructed using the Red recombination system (Datsenko \& Wanner, 2000). To delete the fliC gene, a kanamycin-resistance gene flanked by FLP recognition target sites from plasmid pKD4 was amplified by PCR using primers with regions homologous to the $f l i C$ gene ( $5^{\prime}$-GATCATGGCACAAGTCATTAATACAAACAGCCTGTCGCTGTTGACGTGTAGGCTGGAGC-
TGCTTC-3' and 5' -ATCAATCGCCGGATTAACGCAGTAAAGAGAGGACGTTTTGCGGAACATATGAATATCCTCCTTAGT-3'). Kanamycin-resistant strains were obtained by transforming the PCR products into strain 14028 s harbouring the $\lambda$ Red recombinase on plasmid pKD46. Disruption of the fliC gene was confirmed by PCR using the fliC-specific primers. The kanamycin-resistance gene was then removed by transforming the strain with plasmid pCP20, which expresses the FLP recombinase, resulting in an in-frame deletion of the $f l i C$ gene. The $f l j B, s p i B$ and $s s a V$ genes were deleted in the same way but using the following primers: for $f l j B, 5^{\prime}$-TAACGTAACAGAGACAGCACGTTCTGCGGGACCTGGTTAGCCTG-

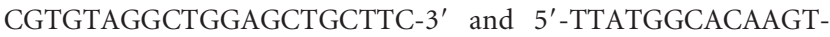
AATCAACACTAACAGTCTGTCGCTGCTGACCCCATATGAATATCCTCCTTAGT-3'; for spiB, 5' -TTACAAGGCCGGGAAGTATGGCTGAATGAAGGTAACCTGTCACTGGTGTAGGCTGGAGCTGCTTC-3' and 5'-GGATAGTTAATCAAAGTATCATAATGTTTAATCGTTACCACATCGCATATGAATATCCTCCTTAGT-3'; and for $s s a V, \quad 5^{\prime}$-AAATTTCTGGAGTCGCAATGCGTTCATGGTTAGGTGAGGGAGTCAGTGTAGGCTGGAGCTGCTTC-3' and 5'-CATTGTCCGCCAACTCCTCTTCGCTAAGGTCAATACTTTCTACCACATATGAATATCCTCCTTAGT-3'. Plasmid pEG9127 is a derivative of pBAC108L and contains the cloned spiC gene (Uchiya et al., 1999). Bacteria were grown at $37^{\circ} \mathrm{C}$ in Luria broth (LB). Kanamycin was used at $50 \mu \mathrm{g} \mathrm{ml}^{-1}$.

RNA preparation and quantitative real-time RT-PCR. Bacteria were grown in LB. When the $\mathrm{OD}_{600}$ of the culture reached 1.8 , total RNA was isolated using an RNeasy kit (Qiagen) in accordance with the manufacturer's protocol. The isolated RNA was treated with DNase I (Invitrogen) to remove contaminating DNA, and $2 \mu \mathrm{g}$ RNA was reverse-transcribed with SuperScript II reverse transcriptase using random primers. Real-time PCRs were performed in $50 \mu \mathrm{l}$ reaction mixtures containing $1 \mu \mathrm{l} \mathrm{cDNA}, 0.9 \mu \mathrm{M}$ of each primer, $0.25 \mu \mathrm{M}$ of each fluorescent probe, and TaqMan Universal Master Mix (Applied Biosystems). Amplification was carried out in 96-well optical plates on a 7300 Real-Time PCR system (Applied Biosystems) with an initial incubation for $2 \mathrm{~min}$ at $50{ }^{\circ} \mathrm{C}$, followed by $10 \mathrm{~min}$ at $95{ }^{\circ} \mathrm{C}$ and then 40 cycles of $95{ }^{\circ} \mathrm{C}$ for $15 \mathrm{~s}$ and $60{ }^{\circ} \mathrm{C}$ for $1 \mathrm{~min}$. The housekeeping gene $16 \mathrm{~S}$ rRNA was used as an internal standard for quantification of the total RNA. The primer pairs and fluorescent probes were designed using Primer Express software version 3.0, and synthesized by Applied Biosystems. The specific fluorescent probes were labelled at the $5^{\prime}$ end with the reporter dye 6-carboxyfluorescein (FAM). The sequences of the primer-probe combinations were as follows: for fliC, $5^{\prime}$ GGATACGCTGAATGTGCAACA-3', 5'-GAGTCACCTCACCGTTCGTCTTA-3', and 6-FAM-CAGGATATGCCGATACTA (fluorescent probe); and for 16S rRNA, 5'-AGATGGGATTAGCTTGTTGGTGA3', 5'-GTAACGTCAATGCTGCGGTTA-3', and 6-FAM-CCACAACACCTTCCTC (fluorescent probe). Threshold cycle values were calculated from the amplification plots, and the amount of $\mathrm{fliC}$ gene expression was determined relative to the level of gene expression in wild-type Salmonella after both values were normalized to $16 \mathrm{~S}$ rRNA levels. Each sample was analysed in triplicate.

Construction of flic-lacZ fusion on a plasmid. To construct a transcriptional fusion of the fliC promoter region to the promoterless lacZ gene in the promoter-probe vector pRL124 (Malo \& Loughlin, 1988), a $0.45 \mathrm{~kb}$ DNA fragment containing the fliC promoter region was amplified by PCR using two primers, 5'-CGGGGTACCGGCTATTTCGCCGCCTAAGA-3' and 5' -CCGGAATTCGCTGTTAGCAGACTGAACCG-3'. The PCR product, digested with KpnI and EcoR1, was ligated into the corresponding sites of pRL124, producing pRL-fliC.

$\boldsymbol{\beta}$-Galactosidase assay. Bacteria were grown overnight in LB at $37^{\circ} \mathrm{C}$, and diluted $1: 100$ into fresh $\mathrm{LB}$ and grown with aeration to $\mathrm{OD}_{600} 1.8$. $\beta$-Galactosidase activity was measured with the substrate 
$o$-nitrophenyl $\beta$-D-galactoside, as described elsewhere (Miller, 1972). Each sample was assayed in triplicate.

Preparation of secreted and whole-cell proteins. An overnight culture in LB was inoculated into $15 \mathrm{ml}$ fresh LB at a $1: 100$ dilution. The cultures were grown at $37{ }^{\circ} \mathrm{C}$ with mild aeration to $\mathrm{OD}_{600} 1.8$. A $1 \mathrm{ml}$ sample of the culture was centrifuged at $18500 \mathrm{~g}$ for $15 \mathrm{~min}$ to remove bacterial cells or supramolecules such as flagella or pili. After filtration through a $0.2 \mu \mathrm{m}$ pore-size filter (Advantec), filtrates were mixed with TCA (final concentration $6 \%$ ), placed on ice for $30 \mathrm{~min}$, and centrifuged at $14000 \mathrm{~g}$ for $20 \mathrm{~min}$. After drying, the pellets were dissolved in $20 \mu \mathrm{l}$ SDS sample buffer (50 mM Tris-HC1, pH 6.8, $2.5 \%$ SDS, $10 \%$ glycerol, $0.01 \%$ bromophenol blue, 25 mM DTT) and boiled for $5 \mathrm{~min}$. For preparation of whole-cell proteins, the bacterial pellet from the centrifugation step was suspended in $1 \mathrm{ml}$ cold water and processed as described above. The pellets were dissolved in $200 \mu \mathrm{l}$ SDS sample buffer and boiled for $5 \mathrm{~min}$.

2D gel electrophoresis. Secreted proteins from bacteria grown to $\mathrm{OD}_{600} 1.8$ were extracted and solubilized in rehydration buffer [8 M urea, $2 \% 3$-[(3-cholamidopropyl)dimethylammonio]-1-propanesulfonate, $0.4 \%$ immobilized $\mathrm{pH}$ gradient buffer ( $\mathrm{pH} 3-10), 0.001 \%$ bromophenol blue and $50 \mathrm{mM} \mathrm{DTT]}$. After quantification of protein by the Bradford assay (Bio-Rad) with BSA as a standard, a total of $125 \mu \mathrm{l}$ lysate containing $50 \mu \mathrm{g}$ protein was applied to $7 \mathrm{~cm}$ IPG ReadyStrips covering a $\mathrm{pH}$ range from 3 to 6 (Bio-Rad). IEF of proteins was carried out with the PROTEAN IEF cell (Bio-Rad) using a preset method that allowed a minimum of $10000 \mathrm{~V}$-h. Focused strips were subjected to SDS-PAGE using a $10 \%$ acrylamide gel and then stained with Bio-Safe Coomassie (Bio-Rad).

Protein identification by MALDI-TOF MS. Protein spots were excised from the Coomassie-stained 2D gels, washed in $1: 1(\mathrm{v} / \mathrm{v}) 25 \mathrm{mM}$ $\mathrm{NH}_{4} \mathrm{HCO}_{3}$ /acetonitrile, and subjected to in-gel digestion with $50 \mathrm{ng}$ trypsin $\mu 1^{-1}$ (Promega) overnight at $37^{\circ} \mathrm{C}$. The extracted peptides were desalted with a ZipTip column (Millipore) and then analysed by MALDI-TOF MS using a Voyager PK2 mass spectrometer (Applied Biosystems). Proteins were identified using the MASCOT program.

Cell culture and bacterial infection. J774 E, a mannose-receptorpositive murine macrophage cell line, was maintained at $37^{\circ} \mathrm{C}$ in an incubator containing $5 \% \mathrm{CO}_{2}$ in Dulbecco's modified Eagle's medium (Sigma-Aldrich) supplemented with $10 \%$ heat-inactivated fetal calf serum (HyClone), $100 \mathrm{U}$ penicillin $\mathrm{ml}^{-1}$, and $100 \mu \mathrm{g}$ streptomycin $\mathrm{ml}^{-1}$. The day before infection, the macrophages were plated at a density of $1.0 \times 10^{6}$ per well in six-well tissue-culture plates (Falcon) or $0.4 \times 10^{6}$ per well in 24 -well plates in medium without antibiotics. Bacteria (25 per macrophage) were added, and the plates were centrifuged at $500 \mathrm{~g}$ for $10 \mathrm{~min}$ at room temperature. The cells were then incubated for $20 \mathrm{~min}$ at $37{ }^{\circ} \mathrm{C}$ to permit phagocytosis, and free bacteria were removed by three washes with PBS (Sigma-Aldrich). After washing, Dulbecco's modified Eagle's medium containing $12 \mu \mathrm{g}$ gentamicin $\mathrm{ml}^{-1}$ was added to kill extracellular bacteria, after which the cells were incubated at $37{ }^{\circ} \mathrm{C}$ for the indicated times.

pcDNA3.1-flic plasmid construction and transfection. The fliC gene was amplified by PCR using the primers $5^{\prime}$-CGGGATCCATGGCACAAGTCATTAATACA-3' and 5'-CCGGAATTTTAACGCAGTAAAGAGAGGAC-3'. The PCR product was digested with $B a m H I$ and EcoRI and then ligated into the corresponding sites of pcDNA3.1 $(+)$ (Invitrogen), producing pcDNA3.1-fliC. The resulting construct was verified by direct sequencing. For transfection experiments, macrophages were plated at a density of $1.0 \times 10^{6}$ per well in six-well plates and then transfected with $2 \mu \mathrm{g}$ pcDNA3.1-fliC plasmid using FuGENE HD transfection reagent (Roche) according to the manufacturer's protocol. After $30 \mathrm{~h}$, cytosolic extracts were prepared from the macrophages and analysed by Western blotting.
For controls, macrophages were transfected with the same amount of empty vector.

Immunofluorescence microscopy. Macrophages were grown on glass coverslips in 24-well cell-culture plates and infected as described above. At $3 \mathrm{~h}$ after infection, samples were fixed in $3.7 \%$ paraformaldehyde for $10 \mathrm{~min}$ and washed three times in PBS. Samples were then permeabilized in $0.2 \%$ Triton X-100 for 10 min to allow entry of the primary antibodies, including rabbit polyclonal anti-Salmonella antibodies (Biodesign) and murine monoclonal antiFliC antibodies (BioLegend). The secondary antibodies were Alexa Fluor 488-conjugated goat anti-rabbit and Alexa Fluor 594-conjugated goat anti-mouse IgG. Samples were mounted onto glass slides using Vectashield (Vector laboratories) and viewed at $\times 63$ magnification on a confocal laser scanning microscope (LSM510 META, Zeiss).

Western blot analysis. Western blot analyses were performed essentially as described previously (Uchiya \& Nikai, 2004). The peptide fragment of the FliC and $\mathrm{FljB}$ polypeptides with a common sequence VQSANSTNSQSDLDSIQ was synthesized, and antiserum specific for the oligopeptide was obtained by immunization of rabbits with the peptide coupled to keyhole limpet haemocyanin using benzidine. The resulting anti-flagellin peptide antibody was used at a dilution of $1: 300$. Cell lysates from macrophages infected with the respective Salmonella strains were prepared, and detection of SOCS-3 protein and the three MAPKs, including extracellular signal-regulated kinase (ERK), p38 and c-Jun amino-terminal kinase (JNK), was performed as described previously (Uchiya $\&$ Nikai, 2005). I $\kappa \mathrm{B}-\alpha$ was detected with a $1: 500$ dilution of anti-I $\kappa$ B- $\alpha$ antibody (Santa Cruz Biotechnology).

Statistical analysis. Each experiment was performed at least three times. The results are expressed as means \pm sDs. The data were analysed by analysis of variance with Dunnett's test. A value of $P<0.05$ was considered statistically significant.

\section{RESULTS}

\section{Identification of flagellin protein by MALDI-TOF MS}

The spiC gene is adjacent to the SpiR (SsrA)/SsrB twocomponent regulatory genes, and is the initial gene of operons that encode the structural and secretory components of SPI-2. In the present study, to further examine the function of SpiC, we carried out a proteomic analysis of the culture supernatant proteins from bacteria grown to $\mathrm{OD}_{600}$ 1.8 in $\mathrm{LB}$, because the expression of the spiC gene has been reported to be induced at $\mathrm{OD}_{600}>1.5$ when the bacteria are grown in LB (K.-i. Uchiya and T. Nikai, unpublished results). We used 2D PAGE to compare the proteins in culture supernatants from the wild-type strain and a spiC mutant, which carries a nonpolar mutation in the spiC gene. The $2 \mathrm{D}$ gel profiles revealed a protein spot (Fig. 1, indicated by black arrowheads) that was more intense in the secreted proteins from the wild-type strain than in those from the spiC mutant. The corresponding spots were excised from the gel, digested with trypsin, and analysed by MALDI-TOF MS. The MASCOT program was employed for the identification of the protein spots. Search results using the NCBlnr protein database showed that protein scores 


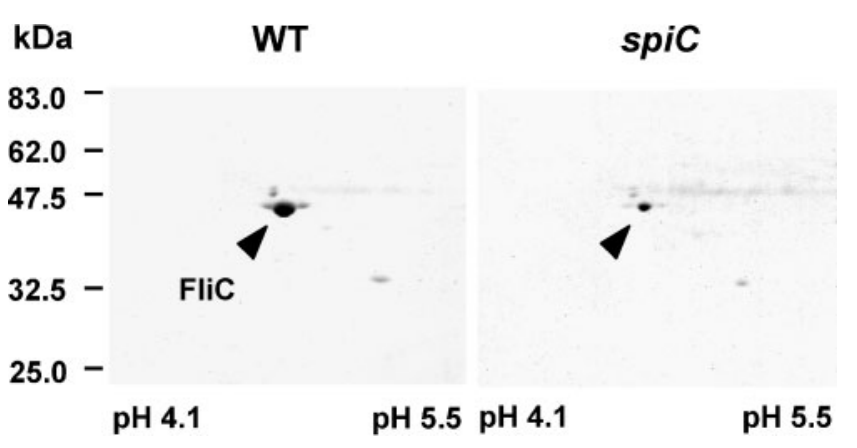

Fig. 1. 2D electrophoretic profiles of culture supernatant proteins from wild-type Salmonella (WT) and its spiC mutant. Bacteria were grown in LB, and the proteins secreted in the media were extracted when the $\mathrm{OD}_{600}$ was 1.8. $2 \mathrm{D}$ gel electrophoresis was performed by using IEF gel strips ( $\mathrm{pH} \mathrm{3-6)} \mathrm{followed} \mathrm{by} \mathrm{SDS-}$ PAGE. The protein spots indicated by the black arrowheads were more intense for wild-type Salmonella than for the spiC mutant. The protein in these spots was identified as FliC by peptide mass fingerprinting using MALDI-TOF MS. The molecular masses and $\mathrm{pH}$ ranges are indicated.

greater than 60 were significant $(P<0.05)$, and there was only one protein with a protein score of 70 . MASCOT identified both spots as containing the flagellin protein FliC, a component of flagellar filaments, suggesting that the absence of SpiC results in a reduction in the level of secreted FliC.

\section{SpiC is involved in the expression of flagellin protein}

S. enterica serovar Typhimurium expresses two antigenically distinct flagellins that are encoded by the $f l i C$ and $f l j B$ genes and coordinately expressed by a phase-variation mechanism (Macnab, 1996). Because these flagellin proteins are exported into the medium from the cytoplasm via the flagellum-specific type III export system (Komoriya et al., 1999; Macnab, 1996), we suspected that SpiC participates in either the transport or the expression of flagellin proteins. To examine these possibilities, we grew the bacteria to $\mathrm{OD}_{600} 1.8$ in $\mathrm{LB}$ to induce the expression of the spiC gene, and then analysed the proteins both in the medium and contained in the cells by Western blotting with a rabbit anti-flagellin antiserum that recognizes a peptide common to FliC and FljB. From their amino acid sequences, FliC and $\mathrm{FljB}$ are predicted to be 51.6 and $52.5 \mathrm{kDa}$, respectively. We observed bands corresponding to FliC and FljB in the wild-type strain. The identities of the two bands were also confirmed by comparison of the patterns from the wild-type, $f l i C, f l j B$ and double-mutant strains (Fig. 2). Although a similar amount of FljB was detected in the wild-type strain and the spiC mutant, in both the culture supernatant and whole-cell lysates, the level of FliC was much lower in the spiC mutant than in the wild-type strain. Complementation of the spiC mutant with a plasmid carrying the wild-type spiC gene (pEG9127) restored FliC to the level found in the wild-type strain. These results demonstrated that SpiC participates in the expression but not the transport of FliC protein.

To determine whether the expression of FliC is regulated at the transcriptional level, we analysed the expression of the fliC gene by fusing the transcriptional regulatory region of fliC to lacZ in pRL124 (Fig. 3a) and by quantitative realtime RT-PCR (Fig. 3b). In both assays, the expression level of the fliC gene in the spiC mutant was greatly reduced compared with the wild-type strain, indicating that SpiC participated in the regulation of FliC transcription.

We further examined the involvement of other SPI-2encoded virulence factors in the expression of the fliC gene. As expected, a mutation in the spiR gene (Ochman et al.,

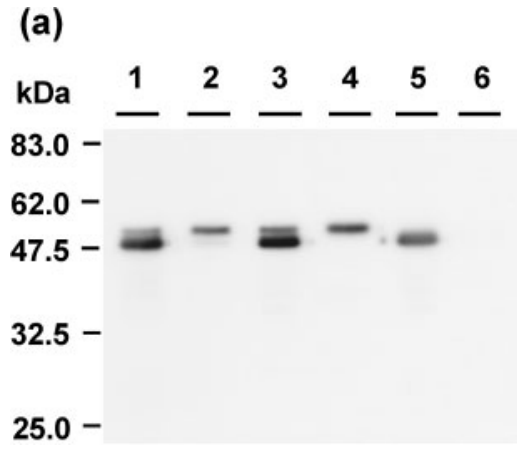

(b)

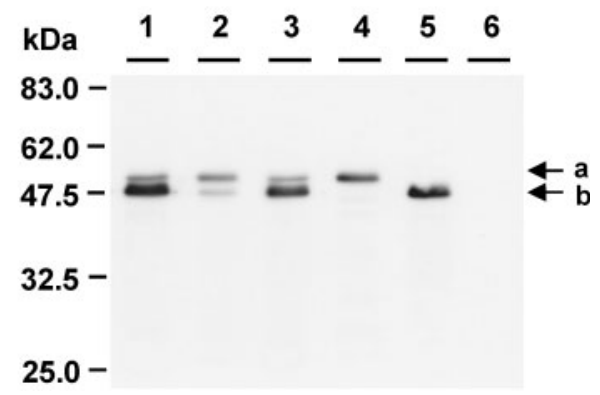

Fig. 2. Detection of flagellin proteins in wild-type and mutant Salmonella strains. Bacteria were cultured in $\mathrm{LB}_{\text {to }} \mathrm{OD}_{600} 1.8$, and secreted proteins (a) and whole-cell proteins (b) were analysed by Western blotting using an anti-flagellin peptide antibody. Lanes: 1, wild-type Salmonella; 2, spiC mutant strain; 3, spiC mutant strain carrying the spiC-containing plasmid pEG9127; 4, fliC mutant strain; 5, fljB mutant strain; 6, fliC/fljB double-mutant strain. In both fractions, the amount of FliC in the spiC mutant was greatly reduced in comparison with wild-type Salmonella. Arrows a and b indicate FljB and FliC proteins, respectively. Molecular masses are indicated to the left of the blots. 
(a)

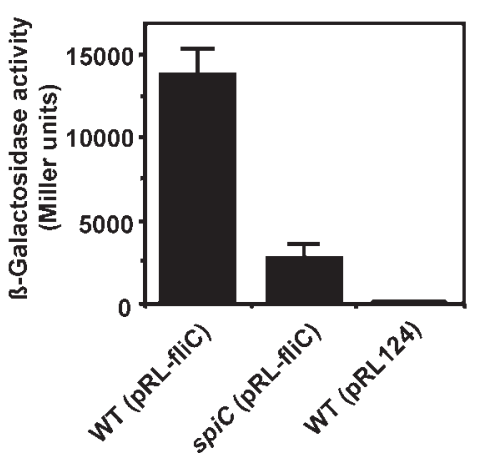

(b)

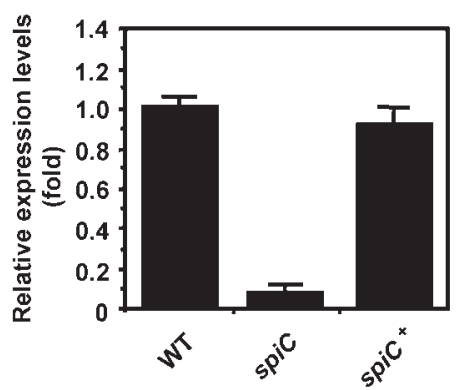

(c)

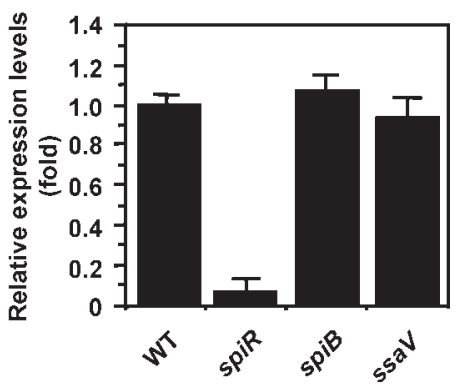

Fig. 3. Expression of the fliC gene in a spiC mutant. (a) $\beta$-Galactosidase activity from a fliC-lac $Z$ transcriptional fusion expressed by wild-type Salmonella (WT) and spiC mutant strain grown in LB to $\mathrm{OD}_{600} 1.8$. $\beta$-Galactosidase activity is expressed as Miller units. WT (pRL124) carries the vector with the promoterless lacZ. (b, c) Quantitative analysis of fliC mRNA expression in mutants for the spiC gene (b) or other SPI-2-encoded genes (c). Bacteria were cultured in LB, and total RNA was extracted from wild-type Salmonella, spiC mutant strain, spiC mutant strain carrying pEG9127 (spiC ${ }^{+}$), spiR mutant strain, spiB mutant strain and ssaV mutant strain when the $\mathrm{OD}_{600}$ was 1.8. Quantitative real-time RT-PCR was conducted using a TaqMan probe. Levels of fliC mRNA were normalized to those of $16 \mathrm{~S}$ rRNA, and the results are shown relative to the expression in wild-type Salmonella.

1996), which is a two-component regulatory gene involved in the expression of SPI-2-encoded genes, resulted in defective expression of the $\mathrm{fliC}$ gene, similar to the spiC mutant (Fig. 3c); however, the defective phenotype was not seen in the $s p i B$ and $s s a V$ mutants, which lack a putative component of the SPI-2 TTSS (Ochman et al., 1996; Hensel et al., 1997). These results suggested the specific involvement of SpiC in the expression of the fliC gene.

\section{Involvement of FliC in the induction of SOCS-3 expression in Salmonella-infected macrophages}

SOCS-3 is known to inhibit cytokine signalling via the Janus kinase/signal transducer and activator of transcription (JAK/STAT) signalling pathway (Kile \& Alexander, 2001; Suzuki et al., 2001). Our previous studies showed that SpiC participates in the induction of SOCS-3 expression by affecting the signal transduction pathways in Salmonella-infected macrophages (Uchiya \& Nikai, 2005); however, the mechanism by which SpiC mediates activation of the signal transduction pathways in macrophages after Salmonella infection remains unknown. Because we found that SpiC contributes to the expression of FliC, we first examined the involvement of FliC in the induction of SOCS-3 expression in macrophages using two methods. In one set of experiments, flagellin (FliC) isolated from S. enterica serovar Typhimurium strain 14028 (Alexis) was added to cell cultures, and in the other set of experiments, macrophages were transfected with the pcDNA3.1-fliC plasmid, which carries the wild-type Salmonella fliC gene. After treatment, cell lysates were prepared and the expression of SOCS-3 was assessed by Western blotting. Treatment of macrophages with purified
FliC induced the dose-dependent expression of SOCS-3 when measured $1.5 \mathrm{~h}$ post-treatment (Fig. $4 \mathrm{a}$ ). The extent of induction was lower $3 \mathrm{~h}$ post-treatment. Furthermore, transfection of macrophages with plasmid pcDNA3.1-fliC resulted in an approximately 1.8-fold increase in SOCS-3 expression compared with the vector control (Fig. 4b), indicating that FliC can induce SOCS-3 expression.

We next examined whether FliC is involved in the induction of SOCS-3 caused by infection of macrophages with Salmonella. Almost no difference was observed between the uptake of bacteria by macrophages infected with the wild-type and that of macrophages infected with mutant Salmonella strains (data not shown). Fig. 5 shows that, at $2.5 \mathrm{~h}$ post-infection, the levels of SOCS-3 in $\mathrm{fliC}$ mutant-infected macrophages were reduced by up to $50 \%$ compared with the levels in wild-type Salmonella-infected macrophages, and that the level of SOCS-3 induced by the fliC/fljB double mutant was twofold lower than that induced by the fliC mutant. Similar patterns of SOCS-3 expression were also observed at $8 \mathrm{~h}$ post-infection, although there were no significant differences at $1 \mathrm{~h}$ post-infection. A mutation of the $f l i B$ gene, however, had little effect on the expression of SOCS-3. Taken together with the results from Figs 2 and 3, these findings demonstrate the involvement of FliC in SPI-2-dependent induction of SOCS-3 expression. Furthermore, the expression of SOCS-3 in macrophages infected with the fliC mutant did not decrease to the level seen for the spiC mutant-infected macrophages. This result indicates that FliC contributes to SPI-2-dependent induction of SOCS-3 expression but that there must also be FliC-independent mechanisms. 
(a)

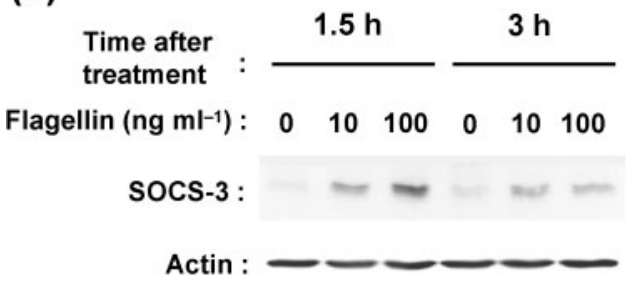

(c)

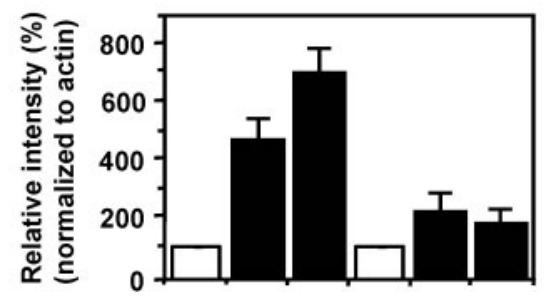

(b)
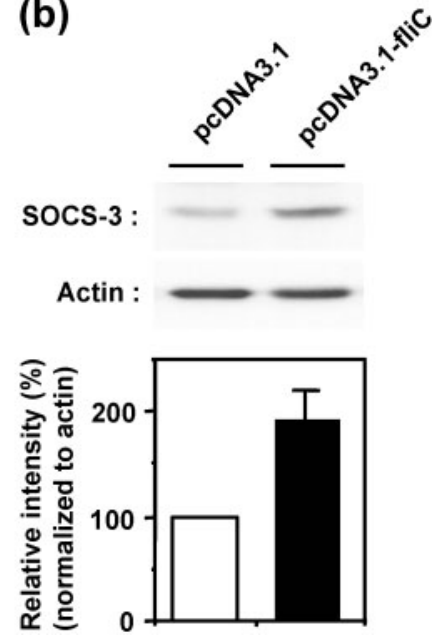

Fig. 4. Involvement of $\mathrm{FliC}$ in the induction of SOCS-3 expression in macrophages. Cytosolic extracts from macrophages treated with purified FliC (a) or transfected with empty vector (pcDNA3.1) or pcDNA3.1-fliC (b) were prepared at the indicated times after treatment and analysed by Western blotting using an anti-SOCS-3 antibody. (c) Levels of SOCS-3 normalized to actin levels. The values are shown relative to untreated or pcDNA3.1transfected cells. Expression of SOCS-3 by macrophages was enhanced by treatment with purified $\mathrm{FliC}$ or by transfection with pcDNA3.1-fliC.

\section{FliC participates in SOCS-3 expression via activation of MAPK pathways}

We next focused on the role of FliC in the signal transduction pathways that govern Salmonella-induced expression of SOCS-3. In a previous study, we showed that both ERK and p38 MAPK signal transduction pathways play important roles in the induction of SOCS3 expression by Salmonella infection (Uchiya \& Nikai, 2005). Therefore, we examined the involvement of FliC in the activation of MAPK pathways by measuring the levels of phosphorylated MAPK in Salmonella-infected macrophages. Western blotting using phospho-specific antibodies (Fig. 6) revealed that the levels of MAPK phosphorylation in Salmonella-infected macrophages corresponded with the levels of SOCS-3 expression. Infection of macrophages with the wild-type strain resulted in higher levels of phosphorylated ERK, p38 and JNK than did infection with the spiC mutant, indicating that SpiC participates in the activation of the MAPK pathways in Salmonella-infected macrophages. The levels of MAPK phosphorylation in the fliC-

(a)
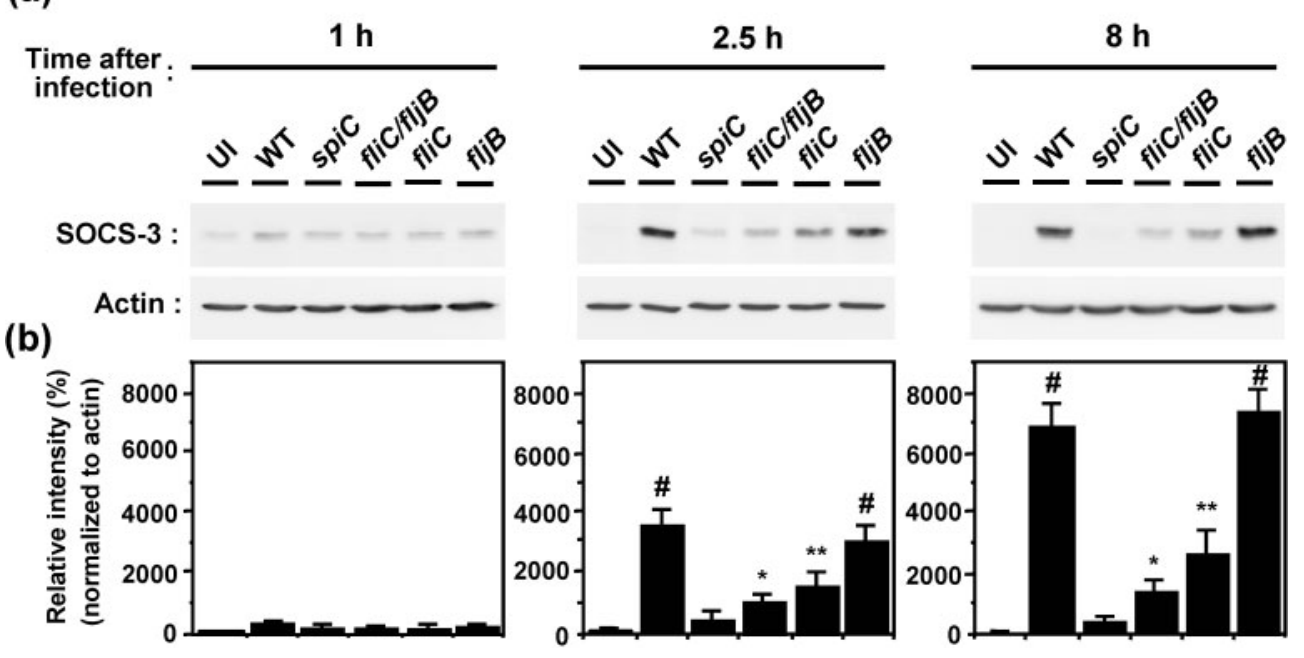

Fig. 5. Western blot analysis of SOCS-3 expression in macrophages infected with Salmonella. Cytosolic extracts from macrophages infected with wild-type (WT), spiC, fliC, fljB or fliC/fljB double-mutant Salmonella were prepared at the indicated times post-infection and were analysed by Western blotting using an anti-SOCS-3 antibody. (a) Images of the original blots. (b) Levels of SOCS-3 normalized to actin levels. The graphs show the percentages compared to uninfected macrophages. The levels of SOCS-3 in the macrophages infected with the fliC or fliC/fljB double mutant were decreased compared with that of wild-type Salmonella-infected cells. ${ }^{*} P<0.05 ;{ }^{\star \star} P<0.005$; $\# P<0.001$, significantly different from macrophages infected with spiC Salmonella. UI, uninfected. 
(a)
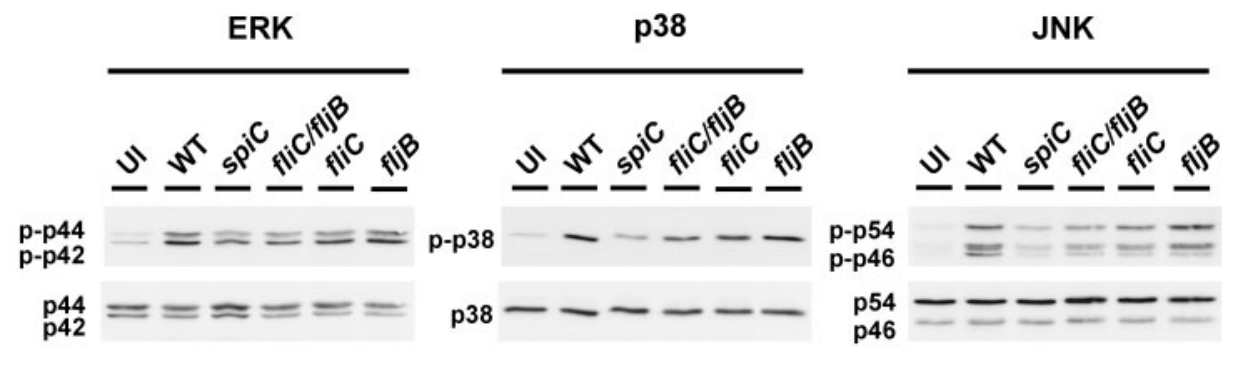

(b)
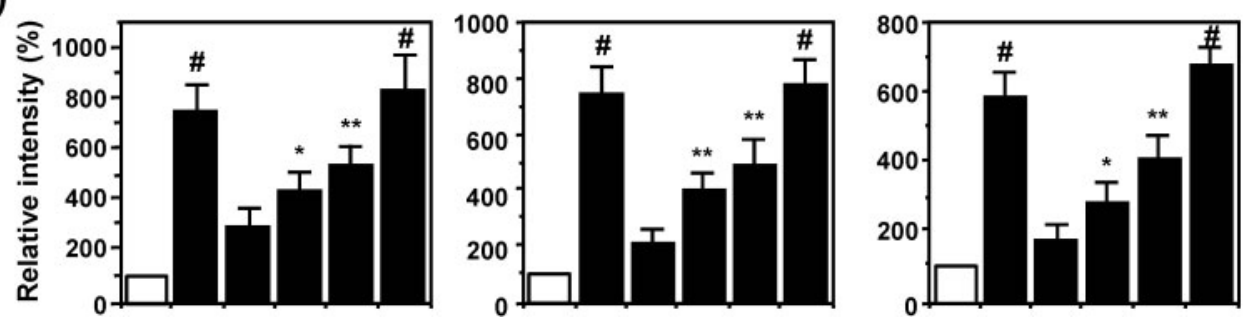

Fig. 6. Western blot analysis of phospho-ERK (p-p44/42), phospho-p38 (p-p38) and phospho-JNK (p-p54/46) in macrophages infected with Salmonella. Cytosolic extracts prepared $2.5 \mathrm{~h}$ after infection with wild-type (WT), spiC, fliC, fljB or fliC/fljB double-mutant Salmonella were analysed with the indicated antibodies. (a) Image of the original blots. After analysis with an anti-phospho-ERK, -phospho-p38 or -phospho-JNK antibody (top), the membranes were stripped and reprobed with an antibody to ERK, p38 or JNK (bottom). (b) Densitometric analysis of the amounts of phospho-ERK (p-p44), phospho-p38 and phospho-JNK (p-p54) normalized to the amounts of ERK (p44), p38 and JNK (p54) in the same samples. The graphs show the percentages compared with uninfected macrophages. The extent of MAPK pathway activation was lower in the fliC mutantinfected cells than in the wild-type Salmonella-infected cells. ${ }^{\star} P<0.05 ;{ }^{\star *} P<0.005 ; \# P<0.001$, significantly different from macrophages infected with spiC Salmonella. UI, uninfected.

mutant-infected macrophages were lower than in the wildtype strain-infected macrophages, but the levels were not as low as those in the spiC mutant-infected macrophages, indicating that the $\mathrm{fliC}$ mutant is weaker in the activation of the MAPK pathways than the spiC mutant. Taken together, these results indicate that FliC partially participates in the SPI-2-dependent expression of SOCS-3 through the activation of the MAPK pathways.

\section{Detection of FliC in Salmonella-infected macrophages}

As FliC was found to be required for the induction of SOCS-3 expression through the activation of MAPK pathways in Salmonella-infected macrophages, we subsequently investigated whether FliC can be detected in Salmonella-infected macrophages by confocal laser scanning microscopy using anti-FliC antibodies. Three hours after bacterial internalization, flagellar filaments composed of FliC were present around bacteria, and detected in about $70 \%$ of macrophages infected with the wild-type strain; however, almost none were observed in macrophages infected by the spiC mutant (Fig. 7). In addition, the defective expression in the spiC mutant could be rescued by introducing pEG9127, which carries the spiC gene. These results suggest that the presence of FliC-derivative filaments inside Salmonella-infected macrophages is important for the induction of SOCS-3 expression.

\section{The NF- $\kappa$ B pathway participates in SpiC- dependent expression of SOCS-3}

Because FliC is reported to activate the NF- $\kappa \mathrm{B}$ pathway in epithelial cells (Ogushi et al., 2001; Reed et al., 2002; Takahashi et al., 2001) and because the NF- $\kappa \mathrm{B}$ pathway participates in the induction of SOCS-3 expression (Hayashi et al., 2002), we investigated the participation of the NF- $\kappa \mathrm{B}$ signalling pathway in SPI-2-dependent expression of SOCS-3. As shown in Fig. 8(a), MG-132, a $\mathrm{NF}-\kappa \mathrm{B}$ inhibitor, dose-dependently reduced the expression of SOCS-3 in wild-type Salmonella-infected macrophages, suggesting the importance of the NF- $\kappa \mathrm{B}$ pathway in Salmonella-induced SOCS-3 expression. To further confirm the participation of the NF- $\kappa \mathrm{B}$ pathway, we measured the level of NF- $\kappa \mathrm{B}$ activation in Salmonella-infected macrophages. In resting cells, NF- $\kappa \mathrm{B}$ makes a complex with the inhibitory protein $\mathrm{I} \kappa \mathrm{B}$ in the cytoplasm (Baldwin, 1996). Upon appropriate cell stimulation, $\mathrm{I} \kappa \mathrm{B}$ is rapidly phosphorylated, ubiquitinated and then degraded by the 26S proteasome (Brown et al., 1995; May \& Ghosh, 1998). This degradation of $\mathrm{I} \kappa \mathrm{B}$ frees $\mathrm{NF}-\kappa \mathrm{B}$ to enter the nucleus and stimulate the transcription of target genes. Therefore, we followed the activation of NF- $\kappa \mathrm{B}$ by measuring the level of $\mathrm{I} \kappa \mathrm{B}-\alpha$ degradation. The experiments were performed in the presence of cycloheximide $\left(0.1 \mu \mathrm{g} \mathrm{ml}^{-1}\right)$ to block the synthesis of new I $\kappa \mathrm{B}-\alpha$. LPS, an activator of NF- $\kappa \mathrm{B}$, was used as a positive control. As shown in Fig. 8(b), the levels of $\mathrm{I} \kappa \mathrm{B}-\alpha$ protein in the wild-type strain-infected macro- 
(a)

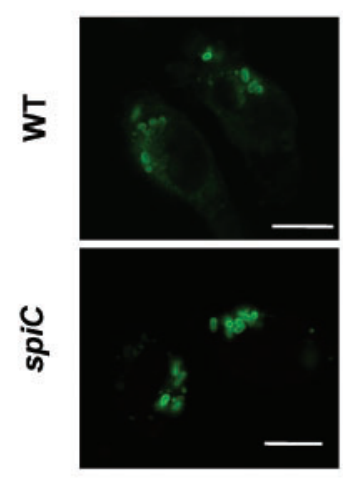

Flic

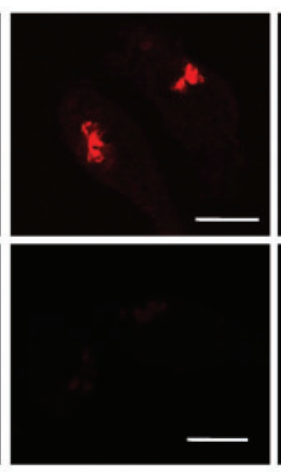

Merged

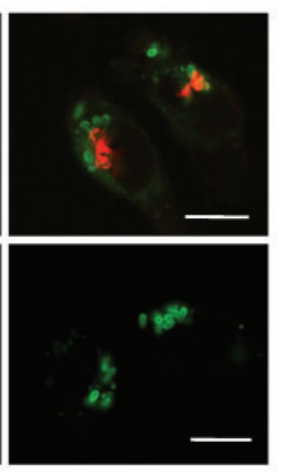

(b)

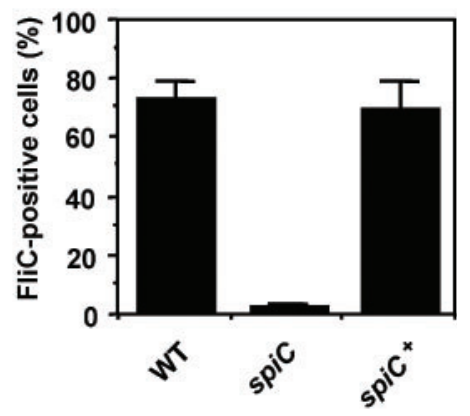

Fig. 7. Confocal immunofluorescence analysis of FliC in macrophages infected with wild-type Salmonella (WT) or spiC mutant strain. Cells were fixed $3 \mathrm{~h}$ after bacterial internalization, and were labelled for Salmonella (green) and FliC (red). (a) Fluorescent images. (b) Percentages of Salmonella-containing macrophages that were stained with an antibody to FliC were enumerated by fluorescence microscopy. FliC was detected in about $70 \%$ of macrophages infected with the wild-type strain, but in almost none infected with the spiC mutant. The defective detection of the spiC mutant could be rescued by introducing pEG9127, which carries the spiC gene. Bars, $10 \mu \mathrm{m}$.

phages at 2.5 and $5 \mathrm{~h}$ post-infection were decreased up to 60 and $45 \%$ compared with those of uninfected macrophages, respectively, whereas infection with the spiC mutant had little effect on the level of $\mathrm{I} \kappa \mathrm{B}-\alpha$ protein.
Taken together, these results demonstrate that the NF- $\kappa \mathrm{B}$ pathway plays a significant role in SPI-2-dependent expression of SOCS-3. In contrast, the fliC mutant and $f l i C / f l j B$ double mutant caused a similar amount of $\mathrm{I} \kappa \mathrm{B}-\alpha$ (a)

(b)

(c)

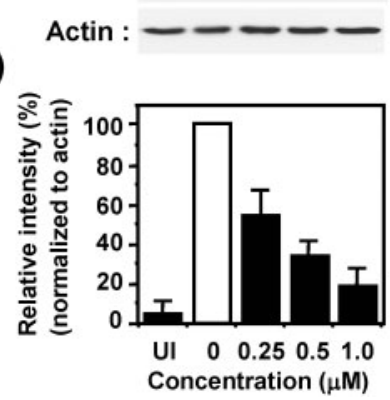

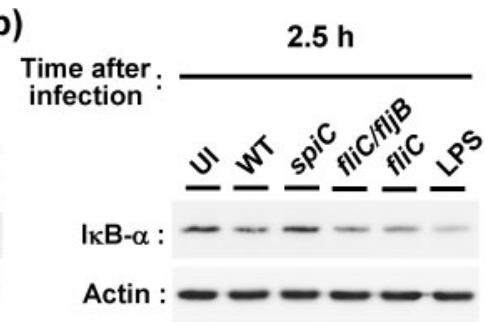

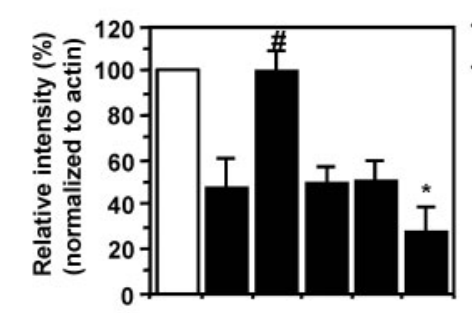

$5 \mathrm{~h}$

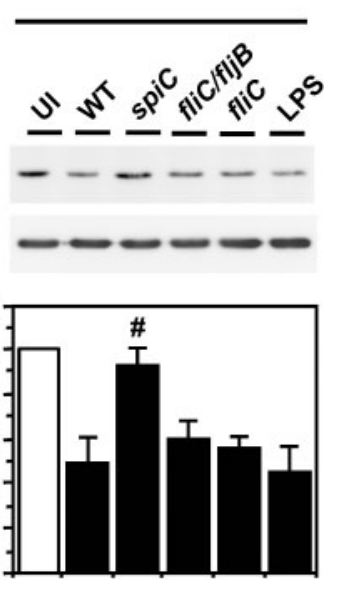

Fig. 8. Involvement of the NF- $\kappa$ B signalling pathway in Salmonella-induced expression of SOCS-3. (a) Effect of the NF- $\kappa$ B inhibitor MG-132 on Salmonella-induced expression of SOCS-3. Macrophages were infected with wild-type Salmonella in the presence of the indicated concentrations of inhibitor or $0.1 \%$ DMSO (solvent control). At $5 \mathrm{~h}$ post-infection, cytosolic extracts were prepared, and SOCS-3 expression was analysed by Western blotting with an anti-SOCS-3 antibody. MG-132 dosedependently suppressed the expression of SOCS-3. (b) Degradation of $\mid \kappa B-\alpha$ in Salmonella-infected macrophages. Macrophages were infected with wild-type or mutant strains of Salmonella in the presence of cycloheximide $\left(0.1 \mu \mathrm{g} \mathrm{l}^{-1}\right)$. Macrophages were also treated with LPS $\left(10 \mu \mathrm{g} \mathrm{ml}^{-1}\right)$ as a positive control. At 2.5 and $5 \mathrm{~h}$ post-infection, cytosolic extracts were prepared, and $\mathrm{I}_{\kappa} \mathrm{B}-\alpha$ degradation was analysed using an anti-I $\mathrm{I}_{\mathrm{B}}-\alpha$ antibody. (c) Levels of SOCS-3 or I $\mathrm{I}_{\mathrm{B}}-\alpha$ normalized to actin levels. The graphs show percentages of the value for untreated or uninfected cells. The NF- $\kappa \mathrm{B}$ pathway participated in the SpiC-dependent but not the FliC-dependent expression of SOCS-3. $\# P<0.001$, significantly different from macrophages infected with the wild-type strain. Ul, uninfected. 
degradation to that of the wild-type strain, indicating that FliC does not participate in the activation of NF- $\kappa \mathrm{B}$ in Salmonella-infected macrophages.

\section{DISCUSSION}

In the current studies, we demonstrated that SpiC, a protein encoded within SPI-2, is involved in the expression of FliC at the transcriptional level. We also showed that the SpiC-dependent expression of FliC plays a significant role in the activation of the signalling pathways that lead to SOCS-3 induction in Salmonella-infected macrophages.

SOCS-3 is a member of the SOCS family, which includes SOCS-1 to -7 and Shc (Starr et al., 1997; Yoshimura et al., 1995). These SOCS proteins act as negative regulators of the JAK/STAT signalling pathway. Ligand binding by cytokine receptors activates JAK, which then phosphorylates STAT proteins. This phosphorylation by JAK is required for the dimerization of STAT and its nuclear translocation, binding of DNA, and activation of gene transcription (Kile \& Alexander, 2001; Yasukawa et al., 1999). In addition to inhibiting the response to IL-6 by blocking the phosphorylation of STAT-3, SOCS-3, like SOCS-1, has been reported to inhibit IFN- $\gamma$ signalling by blocking STAT-1 phosphorylation (Song \& Shuai, 1998; Stoiber et al., 1999). Cytokines, especially IFN- $\gamma$, are essential contributors to macrophage activation, promoting the effective killing of certain intracellular pathogens (Bhardwaj et al., 1986; Green et al., 1990; Suzuki et al., 1988; van Dissel et al., 1987). This suggests that the expression of SOCS-3 affects host defences against intracellular pathogens by inhibiting IFN- $\gamma$ signalling. In our previous studies, cDNA array analysis revealed that the expression of SOCS-3 in Salmonella-infected macrophages is upregulated in a SPI-2-dependent manner, leading to the inhibition of IL- 6 and IFN- $\gamma$ signalling via the JAK/STAT signalling pathway (Uchiya \& Nikai, 2005). This suggested that the expression of SOCS-3 is important for the virulence of Salmonella; however, the mechanism by which SpiC mediates the induction of SOCS-3 expression in macrophages after Salmonella infection remains unknown. It has been reported that SOCS-3 expression is stimulated not only by cytokines but also by PAMPs, such as LPS, bacterial CpG-DNA, and Gram-positive bacteria (Bode et al., 1999; Dalpke et al., 2001; Stoiber et al., 1999, 2001). In the present study, we focused on the role of flagella, which are abundant on the bacterial surface, in SPI-2-dependent expression of SOCS-3.

The flagellum is composed of a basal body, a hook and a filament. Flagellin protein, a component of the filament, is transported from the cytoplasm by the flagellum-specific type III export system (Komoriya et al., 1999) and is polymerized with the help of the cap protein FliD, producing long helical flagellar filaments (Ikeda et al., 1996). S. enterica serovar Typhimurium expresses two antigenically distinct flagellins encoded by the $f l i C$ and $f l j B$ genes. The alternative expression of these two genes is known as phase variation, and it occurs on a timescale of the order of $10^{3}-10^{5}$ generations (Silverman, 1979). In the present study, proteomic analysis revealed that the level of FliC protein is much lower in the culture supernatant from the spiC mutant than in that from the wild-type strain. We further investigated the mechanism by which SpiC alters the levels of secreted FliC. SpiC is required for secretion of some virulence factors from the cytoplasm by the SPI-2 TTSS (Freeman et al., 2002; Yu et al., 2002), although the molecular mechanism is not known. Several genes that encode the SPI-2 TTSS and the flagellum-specific type III export system have sequences in common (Aizawa, 2001; Macnab, 2004). These findings suggest that, in addition to its role in SPI-2 TTSS, SpiC might participate in the export of flagellin proteins from the cytoplasm via the type III flagellar protein export system. Our results showed that the levels of FliC were reduced not only in the culture supernatant but also in whole-cell lysates of the spiC mutant, indicating that the reduced level of FliC was due to altered expression rather than an inability to transport FliC via the type III flagellar protein export system. Furthermore, quantitative real-time RT-PCR revealed that this mutant had a much lower level of fliC mRNA. These results indicate that SpiC controls the expression of FliC at the transcriptional level. A gel-shift assay did not provide evidence that SpiC binds to the promoter region of the $\mathrm{fliC}$ gene (data not shown), which suggests that SpiC participates indirectly in the induction of fliC mRNA expression. We further examined the possibility that SpiC alters flagellar phase variation by using the $f l j B / f l j A$ mutant in which phase variation is eliminated. The $f l j B$ gene constitutes an operon with the $f l i A$ gene, which encodes a negative regulator of $\mathrm{fliC}$ expression (Yamamoto \& Kutsukake, 2006). The expression level of FliC in the $f l j B /$ fljA mutant was decreased by a mutation of the spiC gene (data not shown). This suggests that SpiC is not involved in phase variation, although we cannot completely rule out this possibility. Taken together, these results suggest that SpiC affects the expression of the class 1 gene flhDC or the class 2 gene fliA (Macnab, 1996), which, respectively, function as a master regulator of flagellar gene expression and a regulator of class 3 gene expression. Further studies are needed to clarify how SpiC contributes to the expression of the fliC gene.

The flagellar filament protein FliC is a potent stimulator of immune and proinflammatory responses (Gewirtz et al., 2001b; Hayashi et al., 2001). There have been many reports that it activates signal transduction pathways via TLR5 in cultured cells such as epithelial cells, leading to the induction of immune and proinflammatory genes (EavesPyles et al., 2001; Gewirtz et al., 2001a; Sierro et al., 2001; Zeng et al., 2003). Okugawa et al. (2006) reported the induction of SOCS-1 by flagellin stimulation in Jurkat $\mathrm{T}$ cells. As described above, SpiC contributes to the expression of FliC, suggesting that $\mathrm{FliC}$ participates in SpiC-dependent expression of SOCS-3. As expected, we 
found that the level of SOCS-3 expression in macrophages infected with the fliC mutant was lower than that of the wild-type strain-infected macrophages, whereas a mutation of the $f l j B$ gene had little effect on SOCS-3 expression. These results indicate that FliC plays a significant role in the SpiC-dependent expression of SOCS-3. The level of SOCS-3 expression in the fliC mutant-infected macrophages, however, did not drop to that in spiC mutantinfected macrophages, suggesting the existence of additional FliC-independent mechanisms in the SPI-2-dependent expression of SOCS-3.

In subsequent studies, we focused on the role of FliC in the signal transduction pathways governing the SPI-2-induced expression of SOCS-3. SPI-2-dependent SOCS-3 expression is reported to occur downstream of the ERK and p38 MAPK signalling pathways (Uchiya \& Nikai, 2005). In the present study, we showed that, in addition to ERK and p38 MAPK, the NF- $\kappa \mathrm{B}$ pathway contributes to the SPI-2dependent activation of SOCS-3 expression. In contrast, although FliC was involved in the activation of MAPK pathways, we could not find evidence for the involvement of FliC in NF- $\kappa \mathrm{B}$ activation, indicating that FliC is not required for all aspects of SPI-2-dependent activation of the signal transduction pathways. Flagellin is recognized by TLR5, and ligand binding by TLR5 leads to NF- $\kappa \mathrm{B}$ activation (Hayashi et al., 2001; Zeng et al., 2003). Therefore, our results suggest that FliC activates TLR5independent signal transduction pathways in macrophages. In addition to TLR5, flagellin was recently shown to be recognized in the cytosol by two different nucleotidebinding oligomerization domain (Nod)-like receptors, Ipaf and Naip5 (also known as Bircle) (Molofsky et al., 2006; Ren et al., 2006). Miao et al. (2006) and Franchi et al. (2006) have reported that flagellin activates a signalling pathway independent of TRL5, which leads to caspase-1 cleavage and the secretion of IL- $1 \beta$ via Ipaf in the cytosol of Salmonella-infected macrophages. These findings indicate that Ipaf plays an important role in the induction of SOCS3 expression by FliC in Salmonella-infected macrophages. This possibility is supported by our finding that SOCS-3 expression is elevated in pcDNA3.1-fliC-transfected macrophages.

There are several reports that the expression of FliC is downregulated in Salmonella-infected macrophages or during Salmonella infection in mice (Alaniz et al., 2006; Cummings et al., 2006; Eriksson et al., 2003). However, our data showed that FliC was detected in about $70 \%$ of macrophages infected with the wild-type strain but almost not at all in macrophages infected with the spiC mutant. Lyons et al. (2004) reported that infection of polarized epithelial cells by Salmonella leads to IL- 8 expression by causing the SPI-2-dependent translocation of flagellin to a basolateral membrane domain expressing TLR5. Together with our results, this suggests that SPI-2 mediates not only the transcytosis of flagellin in infected cells but also its expression.
In conclusion, we showed that SpiC is required for the transcriptional expression of flagellin in S. enterica serovar Typhimurium. We also demonstrated that the SpiCdependent expression of FliC activates MAPK signalling pathways in macrophages after Salmonella infection, leading to the induction of SOCS-3 expression. It is likely that these events play important roles in the pathogenesis of Salmonella infection.

\section{ACKNOWLEDGEMENTS}

We are grateful to Sunao Iyoda for helpful discussions. We also wish to thank Asami Sugita, Haruka Amano and Kayo Sobue for technical assistance. This work was supported by Grants-in-Aid for the 'Academic Frontier' Project for Private Universities (2007-2011) from the Ministry of Education, Culture, Sports, Science and Technology of Japan and for Scientific Research (C) 17590403 from the Japan Society for the Promotion of Science (to K.-i. U.).

\section{REFERENCES}

Aizawa, S. I. (2001). Bacterial flagella and type III secretion systems. FEMS Microbiol Lett 202, 157-164.

Akira, S. \& Takeda, K. (2004). Toll-like receptor signalling. Nat Immunol 4, 499-511.

Alaniz, R. C., Cummings, L. A., Bergman, M. A., Rassoulian-Barrett, S. L. \& Cookson, B. T. (2006). Salmonella typhimurium coordinately regulates FliC location and reduces dendritic cell activation and antigen presentation to CD4 ${ }^{+}$T cells. J Immunol 177, 3983-3993.

Baldwin, A. S., Jr (1996). The NF- $\kappa \mathrm{B}$ and $\mathrm{I}-\kappa \mathrm{B}$ proteins: new discoveries and insights. Annu Rev Immunol 14, 649-681.

Bhardwaj, N., Nash, T. W. \& Horwitz, M. A. (1986). Interferon- $\gamma$ activated human monocytes inhibit the intracellular multiplication of Legionella pneumophila. J Immunol 137, 2662-2669.

Bode, J. G., Nimmesgern, A., Schmitz, J., Schaper, F., Schmitt, M., Frisch, W., Häussinger, D., Heinrich, P. C. \& Graeve, L. (1999). LPS and TNF $\alpha$ induce SOCS3 mRNA and inhibit IL-6-induced activation of STAT3 in macrophages. FEBS Lett 463, 365-370.

Bogdan, C. \& Nathan, C. (1993). Modulation of macrophage function by transforming growth factor $\beta$, interleukin-4, and interleukin-10. Ann N Y Acad Sci 685, 713-739.

Brown, K., Gerstberger, S., Carlson, L., Franzoso, G. \& Siebenlist, U. (1995). Control of I kappa B-alpha proteolysis by site-specific, signalinduced phosphorylation. Science 267, 1485-1488.

Cummings, L. A., Wilkerson, W. D., Bergsbaken, T. \& Cookson, B. T. (2006). In vivo, fliC expression by Salmonella enterica serovar Typhimurium is heterogeneous, regulated by ClpX, and anatomically restricted. Mol Microbiol 61, 795-809.

Dalpke, A. H., Opper, S., Zimmermann, S. \& Heeg, K. (2001). Suppressors of cytokine signaling (SOCS)-1 and SOCS-3 are induced by CpG-DNA and modulate cytokine responses in APCs. J Immunol 166, 7082-7089.

Datsenko, K. A. \& Wanner, B. L. (2000). One-step inactivation of chromosomal genes in Escherichia coli K-12 using PCR products. Proc Natl Acad Sci U S A 97, 6640-6645.

Eaves-Pyles, T., Murthy, K., Liaudet, L., Virag, L., Ross, G., Soriano, F. G., Szabo, C. \& Salzman, A. L. (2001). Flagellin, a novel mediator of Salmonella-induced epithelial activation and systemic inflammation: $\mathrm{I} \kappa \mathrm{B} \alpha$ degradation, induction of nitric oxide synthase, induction of 
proinflammatory mediators, and cardiovascular dysfunction. $J$ Immunol 166, 1248-1260.

Eriksson, S., Lucchini, S., Thompson, A., Rhen, M. \& Hinton, J. C. D. (2003). Unravelling the biology of macrophage infection by gene expression profiling of intracellular Salmonella enterica. Mol Microbiol 47, 103-118.

Franchi, L., Am, A., Body-Malapel, M., Kanneganti, T. D., Ozören, N., Jagirdar, R., Inohara, N., Vandenabeele, P., Bertin, J. A. \& other authors (2006). Cytosolic flagellin requires Ipaf for activation of caspase- 1 and interleukin $1 \beta$ in Salmonella-infected macrophages. Nat Immunol 7, 576-582.

Freeman, J. A., Rapple, C., Kuhle, V., Hensel, M. \& Miller, S. I. (2002). $\mathrm{SpiC}$ is required for translocation of Salmonella pathogenicity island 2 effectors and secretion of translocon proteins SseB and SseC. J Bacteriol 184, 4971-4980.

Galan, J. E. (2001). Salmonella interactions with host cells: type III secretion at work. Annu Rev Cell Dev Biol 17, 53-86.

Gewirtz, A. T., Navas, T. A., Lyons, S., Godowski, P. J. \& Madara, J. L. (2001a). Cutting edge: bacterial flagellin activates basolaterally expressed TLR5 to induce epithelial proinflammatory gene expression. J Immunol 167, 1882-1885.

Gewirtz, A. T., Jr, Simon, P. O., Schmitt, C. K., Taylor, L. J., Hagedorn, C. H., O'Brien, A. D., Neish, A. S. \& Madara, J. L. (2001b). Salmonella typhimurium translocates flagellin across intestinal epithelia, inducing a proinflammatory response. J Clin Invest 107, 99-109.

Green, S. J., Crawford, R. M., Hockmeyer, J. T., Meltzer, M. S. \& Nacy, C. A. (1990). Leishmania major amastigotes initiate the L-argininedependent killing mechanism in IFN- $\gamma$-stimulated macrophages by induction of tumor necrosis factor- $\alpha$. J Immunol 145, 4290-4297.

Groisman, E. A., Blanc-Portard, A.-B. \& Uchiya, K. (1999). Pathogenicity islands and the evolution of Salmonella virulence. In Pathogenicity Islands and Other Mobile Virulence Elements, pp. 127150. Edited by J. B. Kaper \& J. Hacker. Washington, DC: American Society for Microbiology.

Hayashi, F., Smith, K. D., Ozinsky, A., Hawn, T. R., Yi, E. C., Goodlett, D. R., Eng, J. K., Akira, S., Underhill, D. M. \& other authors (2001).

The innate immune response to bacterial flagellin is mediated by Tolllike receptor 5. Nature 410, 1099-1103.

Hayashi, T., Kaneda, T., Toyama, Y., Kumegawa, M. \& Hakeda, Y. (2002). Regulation of receptor activator of NF- $\kappa B$ ligand-induced osteoclastogenesis by endogenous interferon- $\beta$ (IFN- $\beta$ ) and suppressors of cytokine signaling (SOCS). J Biol Chem 277, 27880-27886.

Hensel, M., Shea, J. E., Raupach, B., Monack, D., Falkow, S., Gleeson, C., Kubo, T. \& Holden, D. W. (1997). Functional analysis of ssaJ and the ssaK/U operon, 13 genes encoding components of the type III secretion apparatus of Salmonella pathogenicity island 2. Mol Microbiol 24, 155-167.

Hensel, M., Shea, J. E., Waterman, S. R., Mundy, R., Nikolaus, T., Banks, G., Vazquez-Torres, A., Gleeson, C., Fang, F. C. \& other authors (1998). Genes encoding putative effector proteins of the type III secretion system of Salmonella pathogenicity island 2 are required for bacterial virulence and proliferation in macrophages. Mol Microbiol 30, 163-174.

Ikeda, T., Oosawa, K. \& Hotani, H. (1996). Self-assembly of the filament capping protein, FliD, of bacterial flagella into an annular structure. J Mol Biol 259, 679-686.

Janeway, C. A., Jr \& Medzhitov, R. (2002). Innate immune recognition. Annu Rev Immunol 20, 197-216.

Kile, B. T. \& Alexander, W. S. (2001). The suppressors of cytokine signaling (SOCS). Cell Mol Life Sci 58, 1627-1635.

Komoriya, K., Shibano, N., Higano, T., Azuma, N., Yamaguchi, S. \& Aizawa, S. (1999). Flagellar proteins and type III-exported virulence factors are the predominant proteins secreted into the culture media of Salmonella typhimurium. Mol Microbiol 34, 767-779.

Kunkel, S. L., Spengler, M., May, M. A., Spengler, R., Larrick, J. \& Remick, D. (1988). Prostaglandin $\mathrm{E}_{2}$ regulates macrophage-derived tumor necrosis factor gene expression. J Biol Chem 263, 5380-5384.

Lee, A. H., Zareei, M. P. \& Daefler, S. (2002). Identification of a NIPSNAP homologue as host cell target for Salmonella virulence protein SpiC. Cell Microbiol 4, 739-750.

Lyons, S., Wang, L., Casanova, J. E., Sitaraman, S. V., Merlin, D. \& Gewirtz, A. T. (2004). Salmonella typhimurium transcytoses flagellin via an SPI-2-mediated vesicular transport pathway. J Cell Sci 117, 5771-5780.

Macnab, R. M. (1996). Flagella and motility. In Escherichia coli and Salmonella: Cellular and Molecular Biology, 2nd edn, pp. 123-145. Edited by F. C. Neidhardt, R. Curtiss III, J. L. Ingraham, E. C. C. Lin, K. B. Low, B. Magasanik, W. S. Reznikoff, M. Riley, M. Schaechter \& other authors. Washington, DC: American Society for Microbiology. Macnab, R. M. (2004). Type III flagellar protein export and flagellar assembly. Biochim Biophys Acta 1694, 207-217.

Malo, M. S. \& Loughlin, R. E. (1988). Promoter-detection vectors for Escherichia coli with multiple useful features. Gene 64, 207-215.

May, M. J. \& Ghosh, S. (1998). Signal transduction through NF- $\kappa$ B. Immunol Today 19, 80-88.

Miao, E. A., Alpuche-Aranda, C. M., Dors, M., Clark, A. E., Bader, M. W., Miller, S. I. \& Aderem, A. (2006). Cytoplasmic flagellin activates caspase- 1 and secretion of interleukin $1 \beta$ via Ipaf. Nat Immunol 7, $569-575$.

Miller, J. (1972). Experiments in Molecular Genetics, pp. 352-355. Cold Spring Harbor, NY: Cold Spring Harbor Laboratory.

Molofsky, A. B., Byrne, B. G., Whitfield, N. N., Madigan, C. A., Fuse, E. T., Tateda, K. \& Swanson, M. S. (2006). Cytosolic recognition of flagellin by mouse macrophages restricts Legionella pneumophila infection. J Exp Med 203, 1093-1104.

Ochman, H., Soncini, F. C., Solomon, F. \& Groisman, E. A. (1996). Identification of a pathogenicity island required for Salmonella survival in host cells. Proc Natl Acad Sci U S A 93, 7800-7804.

O'Farrell, A. M., Liu, Y., Moore, K. W. \& Mui, A. L.-F. (1998). IL-10 inhibits macrophage activation and proliferation by distinct signaling mechanisms: evidence for Stat 3-dependent and -independent pathways. EMBO J 17, 1006-1018.

Ogushi, K., Wada, A., Niidome, T., Mori, N., Oishi, K., Nagatake, T., Takahashi, A., Asakura, H., Makino, S. \& other authors (2001). Salmonella enteritidis FliC (flagella filament protein) induces human $\beta$-defensin- 2 mRNA production by Caco-2 cells. J Biol Chem 276, 30521-30526.

Okugawa, S., Yanagimoto, S., Tsukada, K., Kitazawa, T., Koike, K., Kimura, S., Nagase, H., Hirai, K. \& Ota, Y. (2006). Bacterial flagellin inhibits $\mathrm{T}$ cell receptor-mediated activation of $\mathrm{T}$ cells by inducing suppressor of cytokine signalling-1 (SOCS-1). Cell Microbiol 8, 1571-1580.

Poltorak, A., He, X., Smirnova, L., Liu, M. Y., Van Huffel, C. X., Birdwell, D., Alejos, E., Silva, M., Galanos, C. \& other authors (1998). Defective LPS signaling in $\mathrm{C} 3 \mathrm{H} / \mathrm{HeJ}$ and $\mathrm{C} 57 \mathrm{BL} / 10 \mathrm{ScCr}$ mice: mutations in Tlr4 gene. Science 282, 2085-2088.

Reed, K. A., Hobert, M. E., Kolenda, C. E., Sands, K. A., Rathman, M., O'Connor, M., Lyons, S., Gewirtz, A. T., Sansonetti, P. J. \& other authors (2002). The Salmonella typhimurium flagellar basal body protein FliE is required for flagellin production and to induce a proinflammatory response in epithelial cells. J Biol Chem 277, 13346-13353.

Ren, T., Zamboni, D. S., Roy, C. R., Dietrich, W. F. \& Vance, R. E. (2006). Flagellin-deficient Legionella mutants evade caspase-1- and Naip5-mediated macrophage immunity. PLoS Pathog 2, e18. 
Schwandner, R., Dziarski, R., Wesche, H., Rothe, M. \& Kirschning, C. J. (1999). Peptidoglycan- and lipoteichoic acid-induced cell activation is mediated by Toll-like receptor 2. J Biol Chem 274, 17406-17409.

Shea, J. E., Hensel, M., Gleeson, C. \& Holden, D. W. (1996). Identification of a virulence locus encoding a second type III secretion system in Salmonella typhimurium. Proc Natl Acad Sci U S A 93, 2593-2597.

Shotland, Y., Krämer, H. \& Groisman, E. A. (2003). The Salmonella SpiC protein targets the mammalian Hook3 protein function to alter cellular trafficking. Mol Microbiol 49, 1565-1576.

Sierro, F., Dubois, B., Coste, A., Kaiserlian, D., Kraehenbuhl, J. P. \& Sirard, J. C. (2001). Flagellin stimulation of intestinal epithelial cells triggers CCL20-mediated migration of dendritic cells. Proc Natl Acad Sci U S A 98, 13722-13727.

Silverman, M. (1979). Phase variation in Salmonella: genetic analysis of a recombinational switch. Proc Natl Acad Sci U S A 76, 391-395.

Song, M. M. \& Shuai, K. (1998). The suppressor of cytokine signaling (SOCS) 1 and SOCS3 but not SOCS2 proteins inhibit interferonmediated antiviral and antiproliferative activities. J Biol Chem 273, 35056-35062.

Starr, R., Willson, T. A., Viney, E. M., Murray, L. J., Rayner, J. R., Jenkins, B. J., Gonda, T. J., Alexander, W. S., Metcalf, D. \& other authors (1997). A family of cytokine-inducible inhibitors of signaling. Nature 387, 917-921.

Stoiber, D., Kovarik, P., Cohney, S., Johnston, J. A., Steinlein, P. \& Decker, T. (1999). Lipopolysaccharide induces in macrophages the synthesis of the suppressor of cytokine signaling 3 and suppresses signal transduction in response to the activating factor IFN- $\gamma . J$ Immunol 163, 2640-2647.

Stoiber, D., Stockinger, S., Steinlein, P., Kovarik, J. \& Decker, T. (2001). Listeria monocytogenes modulates macrophage cytokine responses through STAT serine phosphorylation and the induction of suppressor of cytokine signaling 3. J Immunol 166, 466-472.

Strassmann, G., Patil-koota, V., Finkelman, F., Fong, M. \& Kambayashi, T. (1994). Evidence for the involvement of interleukin 10 in the differential deactivation of murine peritoneal macrophages by prostaglandin $\mathrm{E}_{2}$. J Exp Med 180, 2365-2370.

Suzuki, Y., Orellana, M. A., Schreiber, R. D. \& Remington, J. S. (1988). Interferon- $\gamma$ : the major mediator of resistance against Toxoplasma gondii. Science 240, 516-518.

Suzuki, A., Hanada, T., Mitsuyama, K., Yoshida, T., Kamizono, S., Hoshino, T., Kubo, M., Yamashita, A., Okabe, M. \& other authors (2001). CIS/SOCS3/SSI3 plays a negative regulatory role in STAT3 activation and intestinal inflammation. J Exp Med 193, 471-481.

Takahashi, A., Wada, A., Ogushi, K., Maeda, K., Kawahara, T., Mawatari, K., Kurazono, H., Moss, J., Hirayama, T. \& other authors (2001). Production of $\beta$-defensin-2 by human colonic epithelial cells induced by Salmonella enteritidis flagella filament structural protein. FEBS Lett 508, 484-488.

Uchiya, K. \& Nikai, T. (2004). Salmonella enterica serovar Typhimurium infection induces cyclooxygenase 2 expression in macrophages: involvement of Salmonella pathogenicity island 2 . Infect Immun 72, 6860-6869.

Uchiya, K. \& Nikai, T. (2005). Salmonella pathogenicity island 2dependent expression of suppressor of cytokine signaling 3 in macrophages. Infect Immun 73, 5587-5594.

Uchiya, K., Barbieri, M. A., Funato, K., Shah, A. H., Stahl, P. D. \& Groisman, E. A. (1999). A Salmonella virulence protein that inhibits cellular trafficking. EMBO J 18, 3924-3933.

Uchiya, K., Groisman, E. A. \& Nikai, T. (2004). Involvement of Salmonella pathogenicity island 2 in the up-regulation of interleukin10 expression in macrophages: role of protein kinase A signal pathway. Infect Immun 72, 1964-1973.

van Dissel, J. T., Stikkelbroeck, J. J., Michel, B. B., van den Barselaar, M. T., Leijh, P. C. \& van Furth, R. (1987). Inability of recombinant interferon-gamma to activate the antibacterial activity of mouse peritoneal macrophages against Listeria monocytogenes and Salmonella typhimurium. J Immunol 139, 1673-1678.

Yamamoto, S. \& Kutsukake, K. (2006). FljA-mediated posttranscriptional control of phase 1 flagellin expression in flagellar phase variation of Salmonella enterica serovar Typhimurium. J Bacteriol 188, 958-967.

Yasukawa, H., Misawa, H., Sakamoto, H., Masuhara, M., Sasaki, A., Wakioka, T., Ohtsuka, S., Imaizumi, T., Matsuda, T. \& other authors (1999). The JAK-binding protein JAB inhibits Janus tyrosine kinase activity through binding in the activation loop. EMBO J 18, 13091320.

Yoshimura, A., Ohkubo, T., Kiguchi, T., Jenkins, N. A., Gilbert, D. J., Copeland, N. G., Hara, T. \& Miyajima, A. (1995). A novel cytokineinducible gene CIS encodes an SH-2-containing protein that binds to tyrosine-phosphorylated interleukin 3 and erythropoietin receptors. EMBO J 14, 2816-2826.

Yu, X.-J., Ruiz-Albert, J., Unsworth, K. E., Garvis, S., Liu, M. \& Holden, D. W. (2002). SpiC is required for secretion of Salmonella pathogenicity island 2 type III secretion system proteins. Cell Microbiol 4, 531-540.

Yu, X.-J., Liu, M. \& Holden, D. W. (2004). SsaM and SpiC interact and regulate secretion of Salmonella pathogenicity island 2 type III secretion system effectors and translocators. Mol Microbiol 54, 604619.

Zeng, H., Carlson, A. Q., Guo, Y., Yu, Y., Collier-Hyams, L. S., Madara, J. L., Gewirtz, A. T. \& Neish, A. S. (2003). Flagellin is the major proinflammatory determinant of enteropathogenic Salmonella. J Immunol 171, 3668-3674.

Edited by: J. G. Shaw 